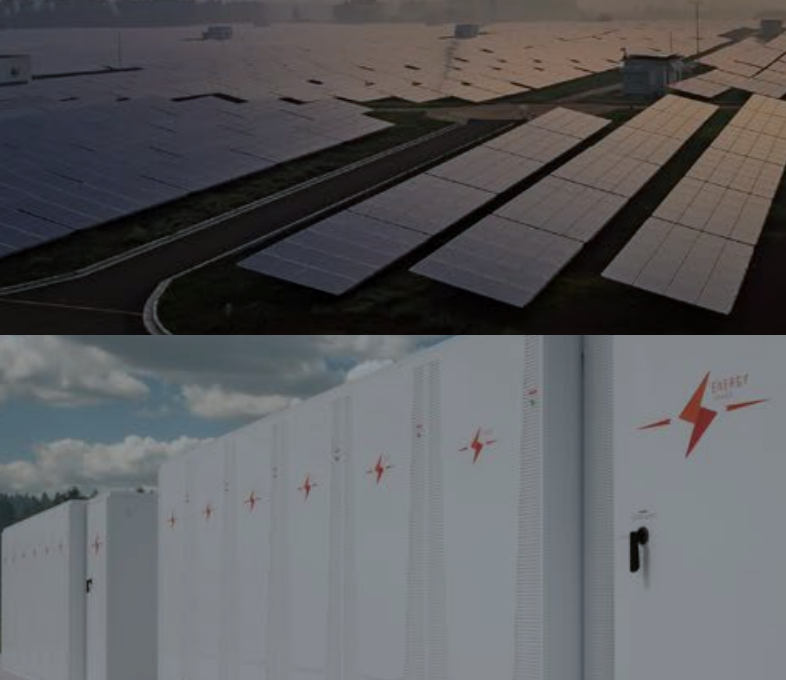

Storage Futures Study

The Challenge of Defining Long-Duration Energy Storage

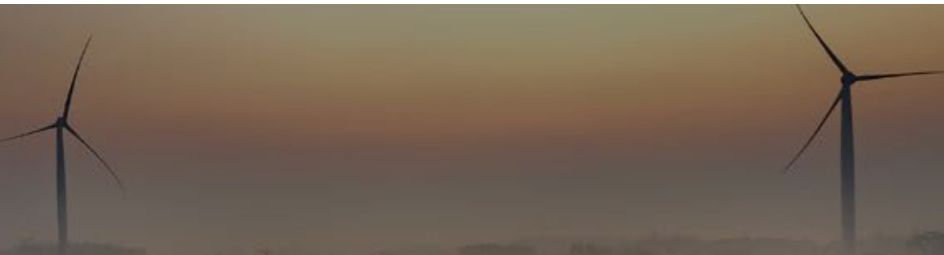




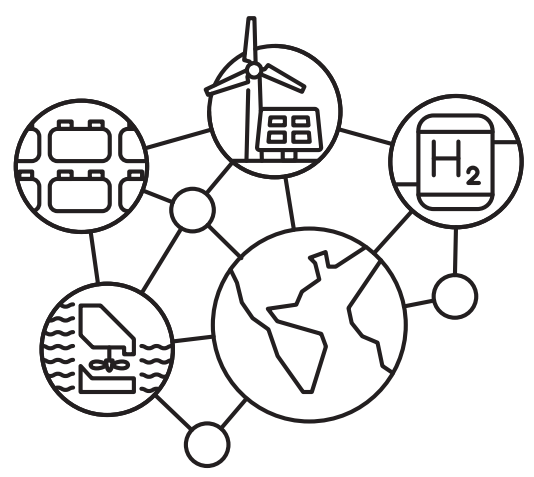

Storage Futures Study

\section{The Challenge of Defining Long-Duration Energy Storage}

Paul Denholm, Wesley Cole, A. Will Frazier, Kara Podkaminer, and Nate Blair 


\section{Acknowledgments}

The authors would like to thank the following individuals for their contributions. Editing and other research support was provided by Claire Bolyard, Michael Deneen, Madeline Geocaris, and Mike Meshek. Helpful review and comments were provided by Sam Baldwin, Jaquelin Cochran, Chris Namovicz, Keith Parks, Gian Porro, and Paul Spitsen.

This work was authored by the National Renewable Energy Laboratory, operated by Alliance for Sustainable Energy, LLC, for the U.S. Department of Energy (DOE) under Contract No. DEAC36-08GO28308. Funding provided by U.S. Department of Energy Office of Energy Efficiency and Renewable Energy Solar Energy Technologies Office, U.S. Department of Energy Office of Energy Efficiency and Renewable Energy Wind Energy Technologies Office, U.S. Department of Energy Office of Energy Efficiency and Renewable Energy Water Power Technologies Office and U.S. Department of Energy Office of Energy Efficiency and Renewable Energy Office of Strategic Analysis. The views expressed herein do not necessarily represent the views of the DOE or the U.S. Government. This report is available at no cost from the National Renewable Energy Laboratory (NREL) at www.nrel.gov/publications. U.S. Department of Energy (DOE) reports produced after 1991 and a growing number of pre-1991 documents are available free via www.OSTI.gov. 


\section{Preface}

This report is one in a series of the National Renewable Energy Laboratory's Storage Futures Study (SFS) publications. The SFS is a multiyear research project that explores the role and impact of energy storage in the evolution and operation of the U.S. power sector. The SFS is designed to examine the potential impact of energy storage technology advancement on the deployment of utility-scale storage and the adoption of distributed storage, and the implications for future power system infrastructure investment and operations. The research findings and supporting data will be published as a series of publications. The table on the next page lists the planned publications and specific research topics they will examine under the SFS.

This document explores the definition of "long duration" as applied to energy storage. Given the growing use of this term, a uniform definition could aid in communication and consistency among various stakeholders. There is large and growing use of the Advanced Research Projects Agency-Energy (ARPA-E) definition of greater than 10 hours. However, the term "longduration energy storage" is often used as shorthand for storage with sufficient duration to provide firm capacity and support grid resource adequacy. The actual duration needed for this application varies significantly from as little as a few hours to potentially multiple days. This dual use of the term means that there cannot be a simple, uniform, and static definition of long-duration storage that captures its ability to provide firm capacity and also aids consistent communication. To address this issue, the National Renewable Energy Laboratory recommends that qualitative descriptions of long-duration energy storage always be accompanied by quantitative descriptions, and that power sector stakeholders be deliberate in how they choose to define longduration energy storage technologies.

The SFS series provides data and analysis in support of the U.S. Department of Energy's Energy Storage Grand Challenge, a comprehensive program to accelerate the development, commercialization, and utilization of next-generation energy storage technologies and sustain American global leadership in energy storage. The Energy Storage Grand Challenge employs a use case framework to ensure storage technologies can cost-effectively meet specific needs, and it incorporates a broad range of technologies in several categories: electrochemical, electromechanical, thermal, flexible generation, flexible buildings, and power electronics.

More information, any supporting data associated with this report, links to other reports in the series, and other information about the broader study are available at https://www.nrel.gov/analysis/storage-futures.html. 


\begin{tabular}{|c|c|c|}
\hline Title & Description & Relation to this Report \\
\hline $\begin{array}{l}\text { The Four Phases of } \\
\text { Storage Deployment: } \\
\text { A Framework for the } \\
\text { Expanding Role of } \\
\text { Storage in the U.S. } \\
\text { Power System }\end{array}$ & $\begin{array}{l}\text { Explores the roles and opportunities for } \\
\text { new, cost-competitive stationary energy } \\
\text { storage with a conceptual framework } \\
\text { based on four phases of current and } \\
\text { potential future storage deployment, and } \\
\text { presents a value proposition for energy } \\
\text { storage that could result in cost-effective } \\
\text { deployments reaching hundreds of } \\
\text { gigawatts (GW) of installed capacity. }\end{array}$ & $\begin{array}{l}\text { Provides broader context on } \\
\text { the implications of the cost } \\
\text { and performance } \\
\text { characteristics discussed in } \\
\text { this report, including the } \\
\text { specific grid services they } \\
\text { may enable in various phases } \\
\text { of storage deployment. This } \\
\text { framework is supported by } \\
\text { the results of scenarios in this } \\
\text { project. }\end{array}$ \\
\hline
\end{tabular}

Energy Storage
Technology Modeling
Input Data Report
Diurnal Storage in the U.S. Power Sector
Reviews the current characteristics of a broad range of mechanical, thermal, and electrochemical storage technologies with application to the power sector. Provides current and future projections of cost, performance characteristics, and locational availability of specific commercial technologies already deployed, including lithium-ion battery systems and pumped storage hydropower.

Assesses the economic potential for utilityscale diurnal storage and the effects that storage capacity additions could have on power system evolution and operations.
Provides detailed background around the battery and pumped storage hydropower cost and performance values used as inputs to the modeling performed in this project.
Features a series of costdriven grid-scale capacity expansion scenarios for the U.S. grid through 2050 and examines the drivers for storage deployment.

Distributed Storage
Customer Adoption
Scenarios

Assesses the customer adoption of distributed diurnal storage for several future scenarios and the implications for the deployment of distributed generation and power system evolution.
Analyzes distributed storage adoption scenarios to test the various cost trajectories and assumptions in parallel to the grid storage deployments.

\section{The Challenge of Defining Long-Duration Energy Storage}

Describes the challenge of a single uniform This report. definition for long-duration energy storage to reflect both duration and application of the stored energy.

\begin{tabular}{ll}
\hline Grid Operational & Assesses the operation and associated \\
Implications of & value streams of energy storage for \\
Widespread Storage & several power system evolution scenarios \\
Deployment & $\begin{array}{l}\text { and explores the implications of seasonal } \\
\text { storage on grid operations. }\end{array}$
\end{tabular}

Grid Operational Implications of Widespread Storage Deployment
Assesses the operation and associated several power system evolution scenarios storage on grid operations.

\begin{abstract}
Considers the operational implications of storage deployment and grid evolution scenarios to examine and expand on the grid-scale scenario results found with the Regional Energy Deployment System (ReEDS).
\end{abstract}

Includes a discussion of all other aspects of the study and provides context for discussion in this report.
Storage Futures Study: Executive Summary and Synthesis of Findings
Synthesizes and summarizes findings from the entire series and related analyses and reports, and identifies topics for further research. 


\section{Table of Contents}

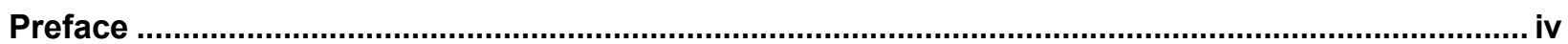

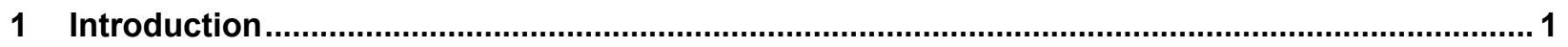

2 First Things First: Defining "Duration” of Energy Storage ...................................................... 2

3 Defining Long Duration To Communicate Consistently............................................................... 3

4 Defining Long Duration To Establish Its Ability To Provide Resource Adequacy ...................... 4

5 A Further Complication: The Impact of Economic and Technology Capabilities ........................ 9

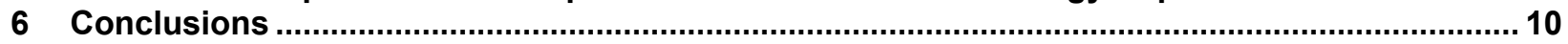

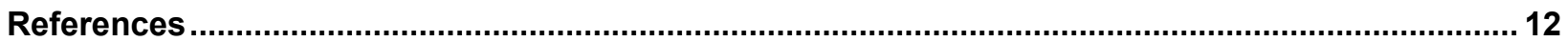




\section{Introduction}

As the share of U.S. power generation from variable renewable energy (VRE) grows, a new vision is taking shape for long-duration energy storage (LDES) to ensure affordable and reliable electricity. In this vision, LDES is deployed at large scale to provide resource adequacy ${ }^{1}$ to the grid and support decarbonization of the electricity system. However, the lack of a uniform definition of LDES inhibits clear communication about the needs of the current and future grid, including scenarios approaching $100 \%$ decarbonization relying primarily on renewable energy.

Energy storage duration is typically expressed in terms of the number of hours a storage device can provide continuous output at its rated capacity. Definitions of LDES in the literature range from as little as 2 hours to as much as multiple days or even months.

There are two main reasons to establish a consistent definition:

1. Create a common language to aid communication to ensure stakeholders are working under consistent assumptions and understanding.

2. Establish characteristics needed to provide firm capacity and support resource adequacy, particularly for establishing regulatory or market rules or other standards.

It is relatively straightforward to define LDES for the first reason (a common communication framework) and a review of the literature suggests durations of at least 10 hours could approach a consensus-based definition, given its current use by a number of industry and government organizations and growing use in the academic and general literature.

We suggest caution in general use of this definition, however, as it inherently conflicts with the second motivation for a definition of LDES (based on its ability to provide firm capacity). This application-based definition has important implications for maintaining a reliable grid, establishing market rules, and optimal planning for decarbonization of the power system.

It is difficult - if not impossible - to reconcile the two different approaches to defining LDES and arrive at a single numerical value for duration (or even range of values) that defines LDES for both ease of communication and using this term as a shorthand description for storage that provides firm capacity. The ability of storage to provide firm capacity (measured in terms of capacity credit) ranges significantly based on regional demand patterns and grid mix, including the amount of renewable energy and storage already in place. Therefore, the duration of storage needed to provide high capacity credit can span an enormous range, from as few as about 2-4 hours for some locations in today's grid to multiple days in future grids with very large renewable energy and storage deployment. As a result, LDES cannot simultaneously have a simple uniform numerical value and be used as a threshold value for measuring capacity credit.

\footnotetext{
${ }^{1}$ Resource adequacy (or simply "adequacy") is defined by the North American Electric Reliability Corporation (NERC) as "The ability of the electric system to supply the aggregate electrical demand and energy requirements of the end-use customers at all times, taking into account scheduled and reasonably expected unscheduled outages of system elements" (1). This includes meeting peak demand during periods of hot or cold weather, during periods of low VRE output, during scheduled or unscheduled plant outages, or during extreme weather.
} 
This discrepancy increases the challenge of communicating the potential role and opportunities for storage of various durations, especially when considering the economics of different technologies that may provide difference services. Regulatory and market frameworks will likely need to evolve to accommodate this reality. However, the lack of a simple uniform definition provides an opportunity to educate key stakeholders about the critical importance of evaluating resource adequacy with increased deployment of renewables and multiple storage technologies.

\section{First Things First: Defining "Duration" of Energy Storage}

First, it is important to establish the definition of storage "duration." This document takes the perspective of the end user of a stationary storage device, including grid planners, operators, and utilities. From this perspective, duration has a fairly straightforward definition summarized by the U.S. Energy Information Administration (2):

The duration of a battery is the length of time that a storage system can sustain power output at its maximum discharge rate, typically expressed in hours. The energy capacity of the battery storage system is defined as the total amount of energy that can be stored or discharged by the battery storage system.

It is important to emphasize that we interpret both energy and duration as measuring the usable energy and duration available to the plant or system operator, net of energy held back to maintain minimum and maximum state of charge or other factors. This means that the amount of usable energy stored is equal to the net power rating multiplied by the duration. For example, a 1-MW (AC rating) battery with 4 hours of duration has $4 \mathrm{MWh}$ of usable stored energy that can be delivered to the grid. The "gross" storage capacity needed to achieve the net capacity is a separate factor determined by the manufacturer or developer to ensure that the net duration is available to the end user.

The use of net vs. gross capacity for defining duration has significant precedent. Pumped storage hydropower plants, which represent the vast majority of energy storage deployed to date, are traditionally measured by the amount of stored water that can actually be used, accounting for the minimum and maximum levels of both the lower and upper reservoir, as opposed to the total amount of water in the reservoir. ${ }^{2}$

Note that this definition describes only the amount of energy stored, not how long it will be stored before use. ${ }^{3}$ However, the two quantities are potentially related as durations increase, as devices with the capacity to store multiple days of energy will likely need to store this energy for multiple days (or longer) before discharging. Finally, this definition doesn't consider the time

\footnotetext{
2 This is also analogous to unusable cushion gas in hydrocarbon storage. In addition, net power ratings of power plants have long been the standard definition of plant power output, accounting for plant operating requirements such as parasitics (e.g., crushers, fans).

${ }^{3}$ One article uses "long term" to measure the amount of time storage is held before discharging, but we found little indication this use is common, and found multiple documents where "term" and "duration" are both used to represent storage capacity $(3,4)$.
} 
needed to charge the device, which can impact the ability of a device to achieve its rated duration for certain applications, as discussed later.

\section{Defining Long Duration To Communicate Consistently}

It can be useful to assign a numerical value to a qualitative adjective used in the power industry for both ease and consistency of communication. For example, we commonly use the terms "distribution" and "transmission" to describe voltage levels within the power grid instead of stating a numerical value. It is easier to use "distribution voltage" instead of "voltage levels at $34.5 \mathrm{kV}$ and below." In these cases, the actual value assigned to this adjective can be somewhat arbitrary, but over time, or through actual standards, the value can become institutionalized or codified.

Given that the term "long-duration energy storage" is already part of the power system vernacular without a clear definition, having a consensus-based duration value would aid in communication.

If this is our primary motivation for defining long-duration, it is probably easiest to use existing literature to derive something close to a consensus value. We can find no evidence that LDES has been defined in a definitive manner by a standards organization such as the International Organization for Standardization or Institute of Electrical and Electronics Engineers.

Table 1 provides a summary of a literature review of 39 documents that define long duration with a numerical value, typically expressed in hours. We identify the type of document, dividing journal articles between those focused on actual grid applications for storage and those that focus on technology development. We exclude definitions published or promoted by individual technology developers. We do not include a large number of documents that discuss LDES in significant detail but do not explicitly define a duration.

Table 1. Sources Defining Long-Duration Storage

\begin{tabular}{|c|c|c|c|c|c|c|c|c|}
\hline \multirow{2}{*}{$\begin{array}{l}\text { Duration } \\
\text { (Hours) }\end{array}$} & \multicolumn{8}{|c|}{ Citation Count (number of cites followed by references) } \\
\hline & $\begin{array}{l}\text { U.S. Dept. } \\
\text { of Energy }\end{array}$ & $\begin{array}{l}\text { Journal } \\
\text { (technology } \\
\text { focus) }\end{array}$ & $\begin{array}{l}\text { National } \\
\text { Lab Report }\end{array}$ & $\begin{array}{l}\text { Journal (grid } \\
\text { focus) }\end{array}$ & Media & $\begin{array}{l}\text { Utility/ } \\
\text { Trade/ } \\
\text { Consultant }\end{array}$ & Other & Total \\
\hline$>2$ & $1(2)$ & & & & & & & 1 \\
\hline$\geq 4$ & & $3(5-7)$ & $2(8,9)$ & $2(10,11)$ & $3(12-14)$ & $2(15,16)$ & $1(17)$ & 13 \\
\hline$\geq 6$ & $1(18)$ & & & & & & & 1 \\
\hline$\geq 8$ & & & & & & $1(19)$ & $1(20)$ & 2 \\
\hline$\geq 10$ & $2(21,22)$ & $2(23,24)$ & & $7(4,25-30)$ & $1(31)$ & & $3(32-34)$ & 15 \\
\hline $\begin{array}{l}\text { Beyond } \\
\text { diurnal }^{a}\end{array}$ & & $1(35)$ & $1(36)$ & $5(3,37-40)$ & & & & 7 \\
\hline Total & 4 & 6 & 3 & 14 & 4 & 3 & 5 & 39 \\
\hline
\end{tabular}

a Typically multiday to seasonal 
While not an exhaustive review, Table 1 demonstrates a large range of definitions, with a significant number of definitions with three threshold values: $\geq 4$ hours, $\geq 10$ hours, and what we call "beyond diurnal," which in the literature generally corresponds to multiday to seasonal storage. This range reflects how different studies of energy storage often consider different aspects, including different technologies (e.g., a battery with 4 hours of capacity, which has longer duration than most currently deployed) or different grid scenarios (e.g., a study of a future grid with very different required attributes than today's). We found several articles that discuss the issues we summarize later in this document, including the challenge of providing a definition that both uses a consistent nomenclature and is based on applications that LDES can serve (41, 42).

Despite the large range in definitions, there appears to be at least some justification for considering $\geq 10$ hours as a consensus duration, based on two factors. First, it has the largest number of citations in our survey. Second, there appears to be growing use of this value following its use by the Advanced Research Projects Agency-Energy (ARPA-E), which defines LDES as 10-100 hours (21). This program and corresponding value is cited specifically in several articles, and more recently this value was used in the U.S. Department of Energy's Long Duration Storage Shot target (22). While the ARPA-E definition also establishes an upper bound, there is little discussion of an upper bound in the literature. However, it may be valuable to establish nomenclature to distinguish between technologies generally thought of as having technical or economic limits to durations much beyond 12 hours to a few days (e.g., pumped storage, many batteries, pumped thermal storage) and those with much longer capacities (multiple days and beyond) that might be better characterized as "seasonal," such as power to gas.

Although it may be possible to apply a 10-plus-hour definition for the sake of convenience, the broad range in definitions from 4 hours to multiple days points to the need to understand these differences. Variation in definitions of LDES can have important consequences if these definitions are used to communicate needs in the current or future grid, or to establish policy or market rules. This leads us to our second motivation and approach to defining LDES, based on services that LDES can provide. This second approach will demonstrate the inherent challenge (or perhaps impossibility) of achieving a uniform definition of LDES.

\section{Defining Long Duration To Establish Its Ability To Provide Resource Adequacy}

In addition to ease of communication, it is also common to assign a numerical value to a qualitative adjective for a variety of regulatory and market reasons. For example, a "major source" for certain emissions is defined by the U.S. Environmental Protection Agency as emitting at least 10 tons/year (43). Even without an underlying regulatory need, it may be useful to generate an application-based threshold for a definition like "long duration." For LDES, this approach to a definition ultimately links a threshold duration value to a specific application-its ability to provide firm capacity.

Energy storage is increasingly being deployed for the purposes of providing firm capacity and supporting resource adequacy. The provision of firm capacity is also a significant aspect of the 
discussion of LDES that appears in the literature. ${ }^{4}$ This also reflects the often-claimed "need" for LDES now or in the near future, where retirements of existing generation assets or growth in electricity demand increase the need for resources that can meet this demand.

Defining LDES in terms of the minimum duration needed to provide firm capacity results in a large range of durations that vary over time and by location. As a result, this approach to a definition ultimately conflicts with our first (consistency and ease of communication).

To explore the possible inconsistency in definitions, we must first examine the capacity credit, or effective load-carrying capability (ELCC) of storage as a function of duration. Simply stated, if 1 MW of storage is to completely replace $1 \mathrm{MW}$ of conventional generation capacity, it needs to have sufficient duration to provide equal or greater capacity credit, or ELCC.

ELCC reflects the ability of a generator to be available during the period of highest risk of an outage, which typically corresponds to periods of peak demand-or, increasingly, peak net demand, where net demand is the normal demand minus the contribution of VRE. Figure 1 shows an example of a simple approximation approach for calculating the duration of storage needed to reduce the net peak load by a certain storage power capacity (essentially representing $100 \%$ capacity credit). In this example we are simulating replacing 1,700 $\mathrm{MW}$ of conventional peaking generation capacity in Florida. We measure the amount of energy needed to reduce the net load by the rated capacity of the storage device, which in this case is about 7,000 MWh, corresponding to about a 4-hour duration.

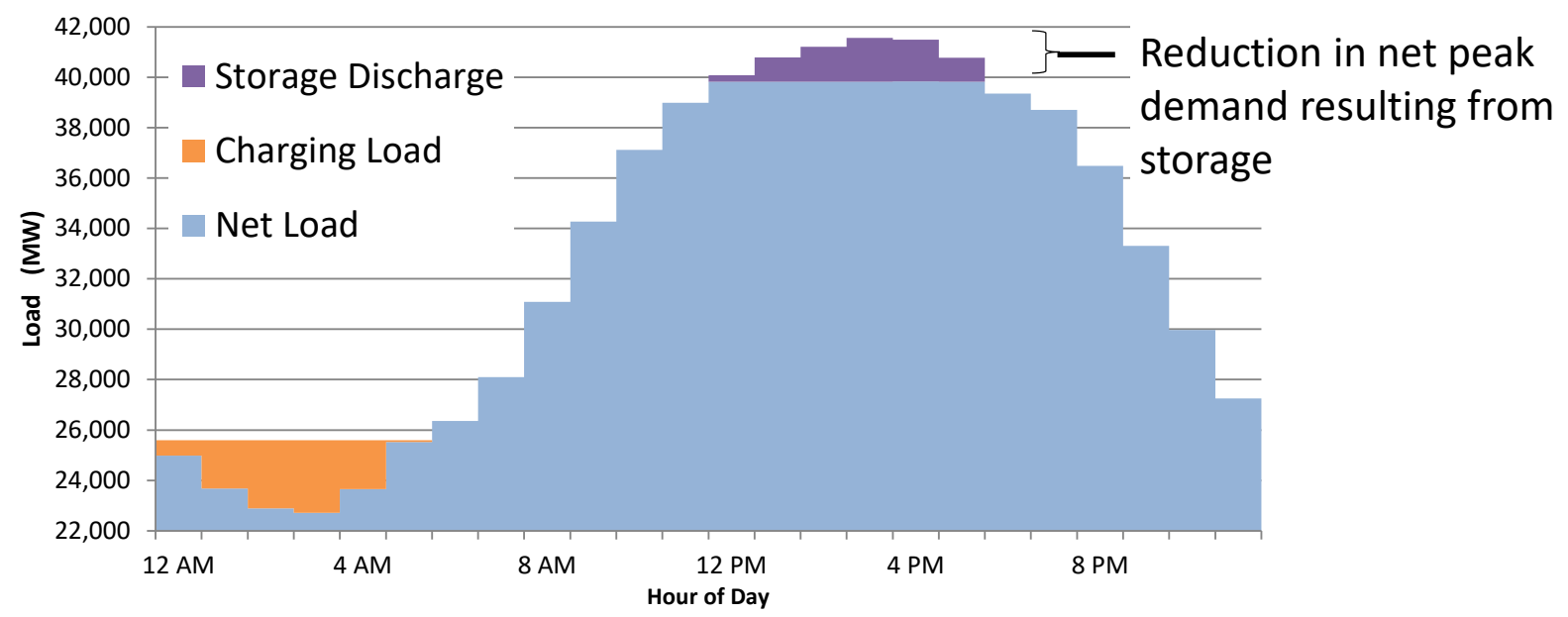

Figure 1. Meeting the peak with energy storage

Simple approaches such as those shown in Figure 1 can be used to estimate the capacity credit of storage as a function of duration, essentially using a linear derate. In our previous example, a 1,700-MW device with 4-hour duration can provide approximately 1,700 MW of ELCC (100\%

\footnotetext{
${ }^{4}$ Many of the documents in Table 1 describe the role of LDES with a variety of terms - including contributing to reliability, addressing shortfalls in renewable energy supply (particularly when evaluating scenarios with high renewable energy deployment), or meeting peak demand during periods of very hot or cold weather. These all are fundamentally describing resource adequacy (1).
} 
capacity credit), and a storage device with the same power rating with 2-hour duration could be derated to $850 \mathrm{MW}$ (meaning it would output $850 \mathrm{MW}$ for 4 hours).

This example for a particular location and grid mix finds that storage with about 4-hour duration can contribute about $100 \%$ of its power rating to system resource adequacy. While this represents an approximation, more detailed probabilistic approaches have found that 4-hour duration storage devices can provide high capacity credit in many parts of the United States that are summer-peaking (44-47). This value also conforms to the threshold value set for full capacity credit established by many market regions in the United States (48). ${ }^{5}$

The implication of this result is that at least in some locations, there is currently no inherent need for storage with at least 10 hours of duration to provide system-level resource adequacy. As a result, an application-based definition of LDES (in terms of minimum duration needed to provide firm capacity) does not match our "ease of communication" definition suggested by the literature (10+ hours). Furthermore, we cannot generate a uniformly consistent application-based definition because the threshold duration value varies greatly due to four main reasons, as discussed in the following sections.

\subsection{Reason \#1: The capacity credit of storage varies based on regional load patterns.}

The ability of storage to serve peak demand periods depends on the shape and duration of those peaks. Figure 2 takes the same approach as in Figure 1, but in this case calculates the duration of storage needed for New York, accounting for the different size of the system. ${ }^{6}$ Because New York experiences longer load peaks (illustrated here by the purple area being wider), that system would require about 5.5 hours to achieve the same net load reduction in proportion to the Florida case above.

\footnotetext{
${ }^{5}$ Establishing the capacity credit of storage as a function of duration is important for many regulatory and market reasons, including the ability of a utility or load-serving entity to meet resource adequacy standards set at the local, state, or regional level. It also establishes the ability of individual plants to receive capacity payments in wholesale markets or as part of power purchase agreements.

${ }^{6}$ The peak load in Florida in this year was about 1.6 times that in New York, so we are simulating a proportionally smaller storage power capacity (1,065 MW in New York vs. 1,740 MW in Florida).
} 


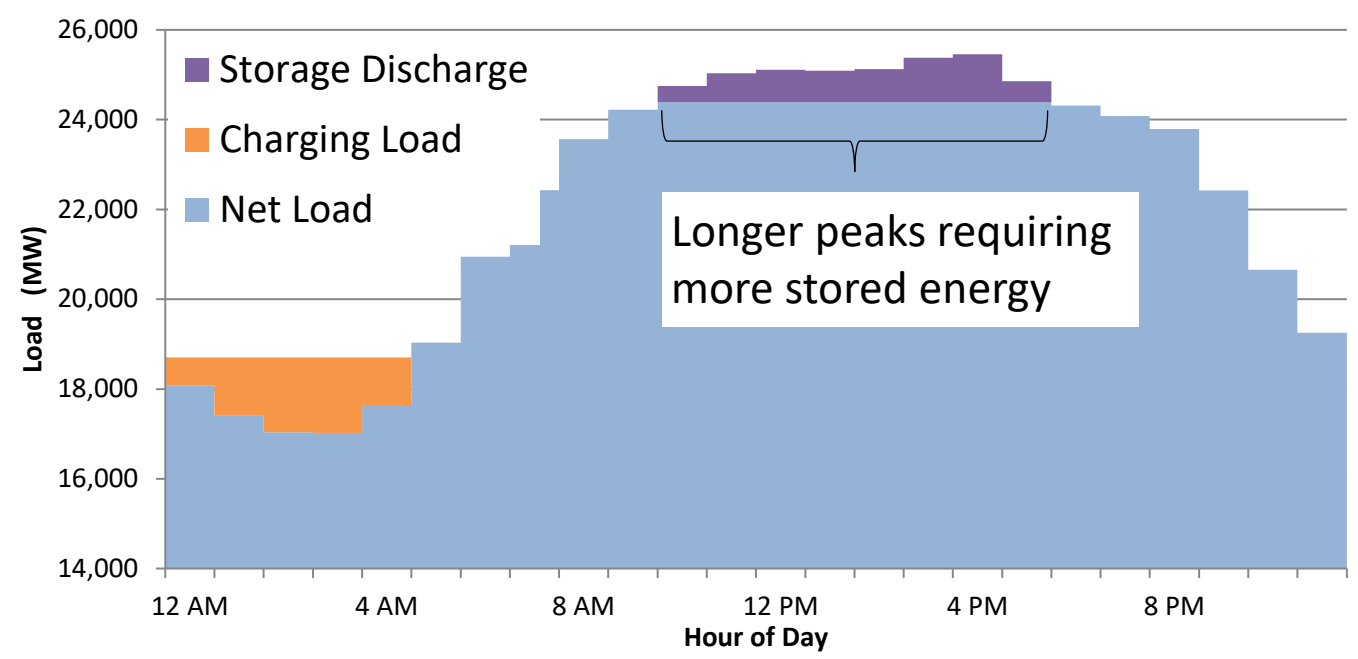

Figure 2. Longer net load peaks decrease the capacity credit of storage (New York example)

In general, longer peaks typically occur in locations that are either less strongly summer-peaking or winter-peaking. This results in a significant regional variation in the capacity credit of storage, and results in different thresholds for durations to achieve $100 \%$ capacity credit.

\subsection{Reason \#2: The capacity credit of storage varies based on renewable energy deployment.}

The length of the net load peak is also impacted by VRE deployment, particularly solar photovoltaics (PV). Figure 3 provides an example illustrating a case where substantially reducing the system peak with storage may require 8 or more hours of duration (blue arrow) with no PV deployed in the system. However, the same system when deriving $20 \%$ of annual energy from PV would require only 4 hours of duration to achieve the same level of net load reduction with storage (gray arrow).

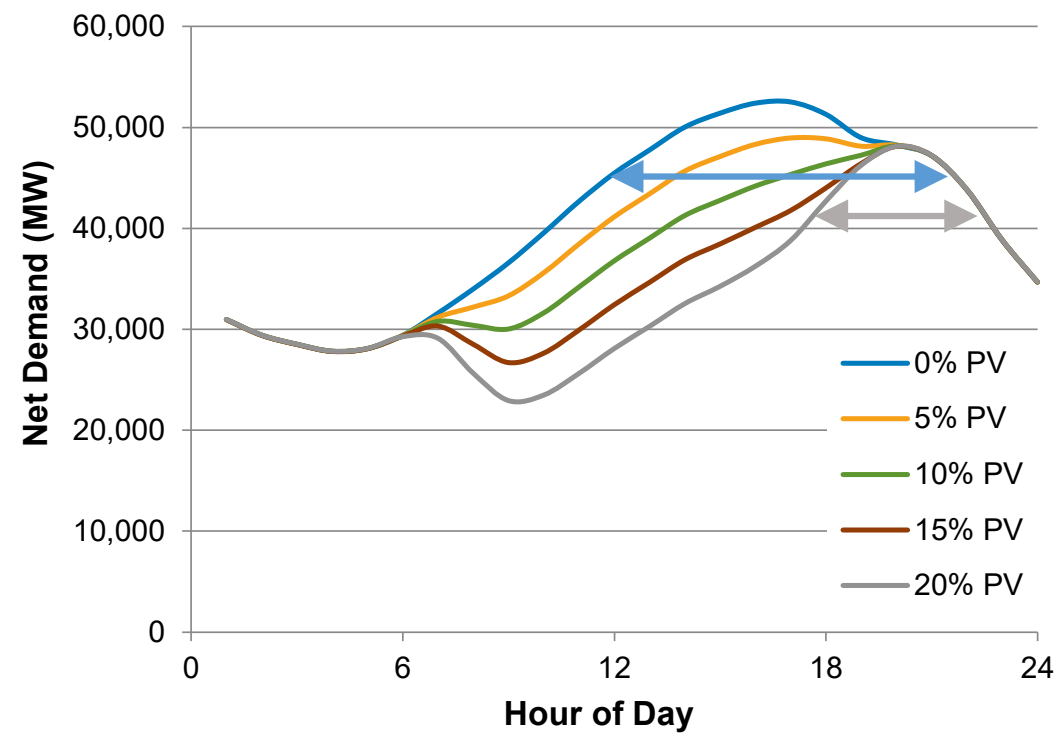

Figure 3. Increased PV deployment narrows the net load peak and increases the capacity credit of storage 
Particularly in strongly summer-peaking systems, PV deployment can substantially alter the capacity credit of storage and therefore reduce the duration of storage required to achieve $100 \%$ capacity credit.

\subsection{Reason \#3: The capacity credit of storage varies based on storage deployment.}

A key element is the impact of storage deployment itself; storage inherently shaves the peak and creates longer net load peaks. Figure 4 provides an example showing how the sequential addition of storage results in wider peaks, using our Florida example.

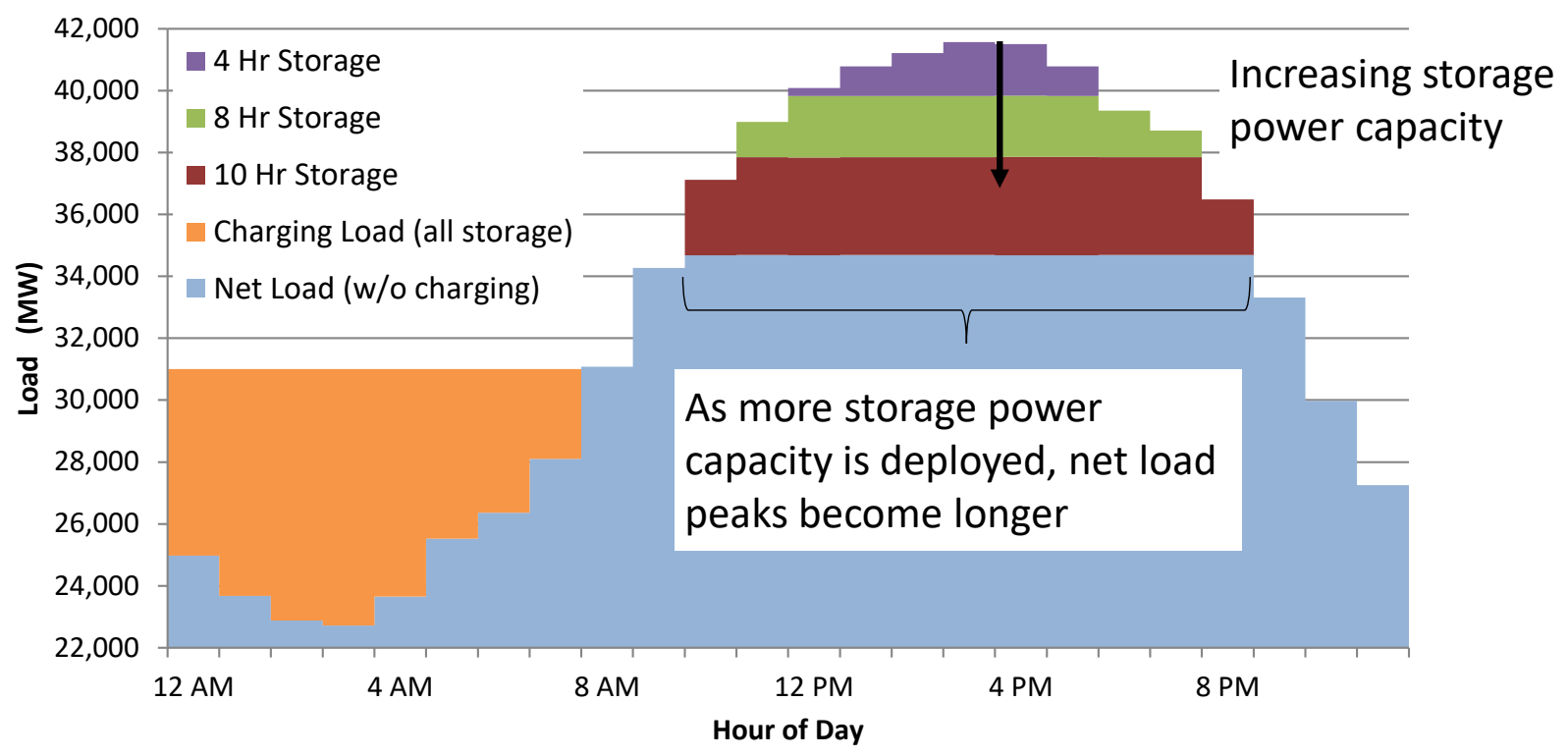

Figure 4. Impact of storage deployment on duration needed

In this example, maintaining high capacity credit requires a transition from 4-hour-duration to eventually 10-hour-duration systems as storage deployment increases.

\subsection{Reason \#4: The capacity credit of even 10+ hour storage technologies may be very low in decarbonized energy systems.}

The example in Figure 4 shows how the addition of storage increases the duration needed for the next unit of storage to maintain high capacity credit. While this can be offset to some extent with additional PV (Figure 3), at some point peak net loads can be shifted to periods of relatively low PV (and wind) output. With enough VRE and storage deployment, peak net load periods can last several days, which would require further storage deployments to have corresponding durations to maintain high capacity credit. A number of studies, including several in Table 1, examine scenarios that approach or achieve 100\% renewable energy supply and identify the potential need for storage to charge weeks or even months before periods of high net demand, and then discharge for multiple days (48). In these cases, 10 hours of storage can have very low capacity credit, and even 100 hours may be insufficient for some applications such as addressing extended outages of transmission in congested load pockets. 
Overall, these four reasons likely explain much of the discrepancy in definitions seen in Table 1. Definitions of LDES that emphasize its ability to provide firm capacity span a wide range of use cases and grid conditions. Definitions that use 4-hour duration may be considering the current or historical grid, where 4 hours may be sufficient to meet peak summer demand. Definitions that use a duration of more than 4 hours may reflect current systems that are winter-peaking, or nearfuture systems where shifting load patterns and increased storage deployments result in net load peaks that are longer than 4-hours. In addition, LDES definitions of days and beyond are often based on studies of grids that rely mostly on VRE and may require sufficient stored energy to address multiday periods of below-average wind or solar energy supply.

\section{A Further Complication: The Impact of Economic and Technology Capabilities}

The previous examples show that there is a wide range in the duration threshold needed for high capacity credit. However, communicating this in terms of a "need" for long-duration storage (or any specific minimum duration) overlooks the more fundamental issue that this need is ultimately driven by the economics of competing storage options, including the potential role of shorter-duration storage appropriately derated. For example, Figure 5 shows a scenario in which the combination of VRE and storage produces net load peaks of about 10 hours. ${ }^{7}$ As discussed previously, this could be provided by a 10-hour duration device, or a 6-hour duration device derated to $60 \%$ power capacity. In these cases, the derate means that the power component of the shorter-duration storage system is potentially oversized (more costly) relative to the longerduration system. However, this oversized power capacity provides the plant additional opportunity to charge during high-power curtailment events, particularly in scenarios of significant PV deployment. This is illustrated in Figure 5 by the surplus generation window, where a derated 6-hour duration device can take advantage of its ability to charge for shorter durations at high power, providing energy time-shifting opportunities that may partially or completely offset the increase in power-related costs.

\footnotetext{
${ }^{7}$ This image shows a simulation of four days in January in 2050 in a region of the eastern United States from a study where renewable energy provides about $80 \%$ of the nation's electricity (50).
} 


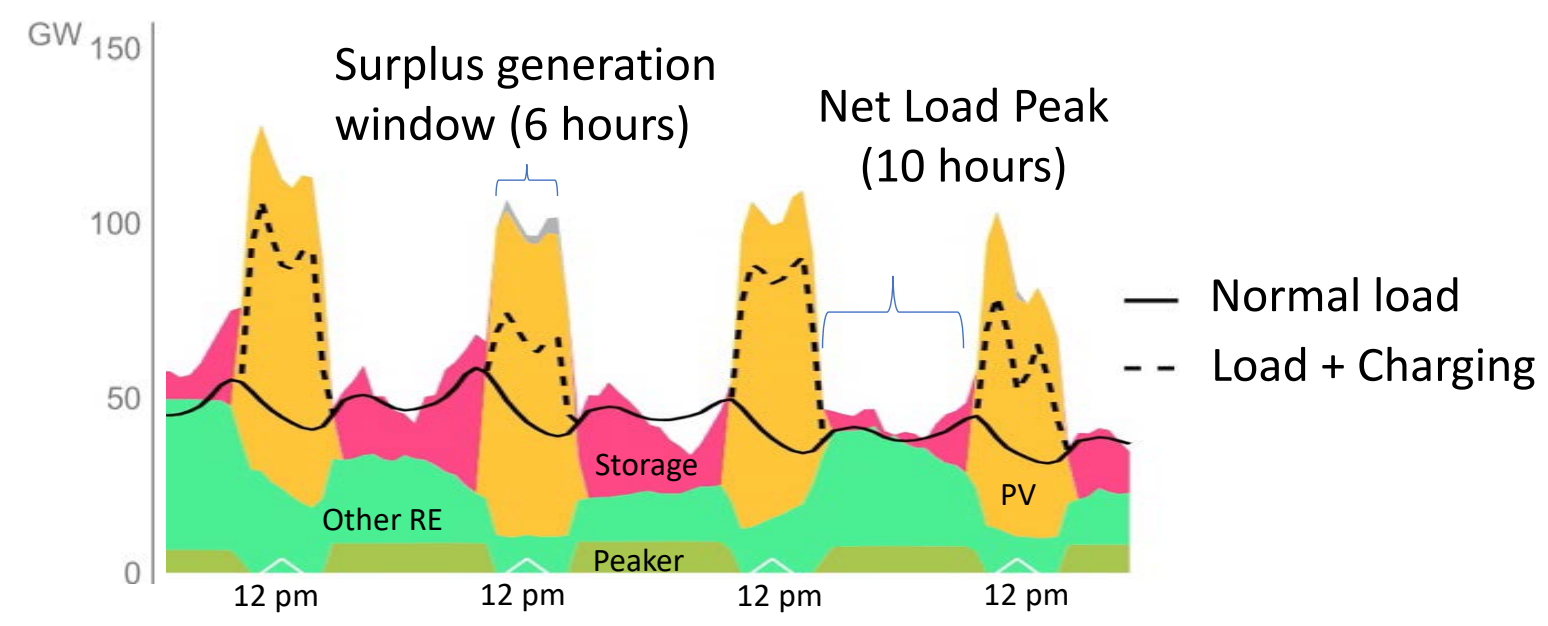

Figure 5. Opportunities for derated storage devices to take advantage of high-power curtailment events

The relative power capacities of charging and discharging also places limits to what longduration storage can achieve in terms of usable duration. If we assume our storage device in Figure 5 has the same charge and discharge rate, then a 10-hour duration device with an $80 \%$ round-trip efficiency (RTE) would require 14 hours to charge, representing 24 hours of continuous operation (either charging or discharging at $100 \%$ of rated power), which is the upper bound of feasible daily operation. This operation would also require energy from the grid to be available during the entire 14-hour period when the storage device is not discharging. In reality, there may be shorter periods of low-cost, off-peak generation available for charging, which could require a higher power rating to charge to meet the duration requirement. This all points to the fact that high capacity credit cannot be based solely on the duration of the stored energy, but also its ability to recharge in a timely and economic manner, and any definition of LDES must account for this limitation.

Ultimately, the choice between technologies is driven by economics, which adds yet another dimension to defining long-duration storage. In some cases the "need" for storage with long duration could be met with derated shorter-duration storage, whose loss in capacity value can be offset by increased energy value from more flexible operation.

\section{Conclusions}

The growing role of variable generation resources in the power grid has led to the perception, with significant analytic basis, that there will ultimately be a need to move beyond storage deployments with 4 hours of duration, currently dominated by lithium-ion batteries. This perception has resulted in calls for the use of long-duration energy storage, recognizing the potential for net load peaks that may extend to 8 or more hours under various scenarios of storage and renewable energy deployment. Yet the lack of a uniform definition of long duration inhibits a clear communication about the needs of the current and future grid, including scenarios approaching 100\% decarbonization relying primarily on renewable energy.

Because of the different motivations and practices for how long-duration storage is discussed and analyzed, we do not recommend that a single definition for long-duration storage be used. Although a single qualitative duration threshold for LDES would be useful for communications, 
it is ultimately too arbitrary and does not identify the duration required for storage to provide resource adequacy to the grid as it evolves. However, we do recommend that qualitative descriptions for storage duration should always be accompanied by a quantitative definition (e.g., "in this work we consider long-duration storage systems to have duration of 4 or more hours"). Further, we recommend that analysts and others who are active in the storage space consider why they have chosen their definitions.

For those who are simply looking to adopt a long-duration storage definition for convenience, we recommend using ARPA-E's definition of 10-100 hours given that (1) this time frame fulfills the "high capacity credit" requirement until systems are approaching $80 \%$ or more VRE contributions (with commensurate deployments of storage technologies), (2) it aligns with the largest share of literature citations, and (3) it provides a fairly clear distinction between incumbent technologies such as lithium-ion batteries and truly seasonal storage technologies such as hydrogen or power to gas.

However, we believe that caution is needed, particularly if the use of the term is used to imply a systemwide need to support resource adequacy. Claims that 10-hour duration of storage is needed to provide resource adequacy in the current grid does not align with analysis that shows 4 hours can be largely sufficient, at least in the near term and in some regions. Furthermore, the need for durations of more than 4 hours is lessened by the increased deployment of solar PV and the ability to derate shorter-duration storage (if sufficiently cost-effective), making the need for technologies with specific durations as much of an economic issue as a technical one. Therefore, the need for storage with durations of 10 or more hours largely hinges on a future grid with a specific set of conditions including regional load patterns, renewable energy deployment, previous storage deployments, and the economics of competing storage options. Finally, as diurnal storage deployment increases, there is a point at which multiday to seasonal storage may be necessary to support resource adequacy and to allow further cost-effective decarbonization of renewable resources.

As a result, there cannot be a uniform and broadly applicable definition of LDES that has as an underlying basis its ability to support resource adequacy. This outcome may be somewhat inconclusive but reflects the growing complexity of resource adequacy assessment in general. Many resources, including wind, solar PV, and demand response have time-, region-, and deployment-based variations in capacity credit. Regulatory and market frameworks will need to evolve to accommodate this reality. The role of storage of varying durations will ultimately be determined by their economic costs and benefits for providing resource adequacy and the other services that storage can provide.

We believe that as researchers, analysts, and others carefully consider the motivation of their chosen storage definitions, communication among stakeholders will improve and we will be able to collectively advance the understanding of the role of storage in power systems. 


\section{References}

1. North American Electric Reliability Corporation (NERC). 2021. Glossary of Terms Used in NERC Reliability Standards. Washington, D.C.: NERC.

https://www.nerc.com/files/glossary_of terms.pdf

2. U.S. Energy Information Administration (EIA). 2020. Battery Storage in the United States: An Update on Market Trends. Washington, D.C.: EIA. https://www.eia.gov/analysis/studies/electricity/batterystorage/pdf/battery_storage.pdf

3. S. Gonzato, K. Bruninx, and E. Delarue. 2021. "Long term storage in generation expansion planning models with a reduced temporal scope." Applied Energy 298: 117168. https://doi.org/10.1016/j.apenergy.2021.117168

4. J. J. Hargreaves and R. A. Jones. 2020. "Long Term Energy Storage in Highly Renewable Systems." Frontiers in Energy Research 8: 219. https://doi.org/10.3389/fenrg.2020.00219

5. R. E. Ciez and D. Steingart. 2020. "Asymptotic Cost Analysis of Intercalation Lithium-Ion Systems for Multi-hour Duration Energy Storage.” Joule 4: 597-614. https://doi.org/10.1016/j.joule.2020.01.007

6. G. F. Frate, L. Ferrari, and U. Desideri. 2020. "Multi-Criteria Economic Analysis of a Pumped Thermal Electricity Storage (PTES) With Thermal Integration." Frontiers in Energy Research 8. https://doi.org/10.3389/fenrg.2020.00053

7. P. Byrne and P. Lalanne. 2021. "Parametric Study of a Long-Duration Energy Storage Using Pumped-Hydro and Carbon Dioxide Transcritical Cycles." Energies 14. https://doi.org/10.3390/en14154401

8. M. Kintner-Meyer, P. Balducci, W. Colella, M. Elizondo, C. Jin, T. Nguyen, V. Viswanathan, and Y. Zhang. 2012. National Assessment of Energy Storage for Grid Balancing and Arbitrage: Phase 1, WECC. Richland, WA: Pacific Northwest National Laboratory. https://www.pnnl.gov/main/publications/external/technical_reports/PNNL21388.pdf

9. Sandia National Laboratories. 2021. ISSUE BRIEF Long-Duration Energy Storage. Albuquerque, NM: Sandia National Laboratories. https://www.sandia.gov/ess-ssl/wpcontent/uploads/2021/01/Issue-Brief-Long-Duration-Energy-Storage-January-2021_v2.pdf

10. J. G. Simpson, G. Hanrahan, E. Loth, G. M. Koenig, and D. R. Sadoway. 2021. "Liquid metal battery storage in an offshore wind turbine: Concept and economic analysis." Renewable and Sustainable Energy Reviews 149: 111387. https://doi.org/10.1016/j.rser.2021.111387

11. U. Helman, B. Kaun, and J. Stekli. 2020. "Development of Long-Duration Energy Storage Projects in Electric Power Systems in the United States: A Survey of Factors Which Are Shaping the Market." Frontiers in Energy Research 8: 275. https://doi.org/10.3389/fenrg.2020.539752 
12. L. Collins. 2021. "Long-duration energy storage set for 'very steep' growth as sector enters commercial phase." Recharge News. https://www.rechargenews.com/technology/longduration-energy-storage-set-for-very-steep-growth-as-sector-enters-commercial-phase/2-1$\underline{966326}$

13. A. Grundy and A. Colthorpe. 2020. "Contenders: Long duration energy storage technologies, and who's behind them." Energy Storage News. https://www.energystorage.news/contenders-long-duration-energy-storage-technologies-and-whos-behind$\underline{\text { them/ }}$

14. F. Mayr and F. Oldenburg. 2021. "'Longer-duration storage' and its role in the future of energy." Energy Storage News. https://www.energy-storage.news/longer-duration-storageand-its-role-in-the-future-of-energy/

15. E. Childs, M. Roumpani, S. Dueñas, P. Sanchez, J. Gorman, M. Davidson, and L. Backer. 2020. Long Duration Energy Storage for California's Clean, Reliable Grid. Berkeley, CA: Strategen Consulting, LLC.

16. Wood Mackenzie Power \& Renewables. 2020. U.S. Energy Storage Monitor.

17. N. Gallardo. 2021. "Long-duration energy storage: a technoeconomic comparative analysis with case studies in Mexico." Master's thesis, KTH School of Industrial Engineering and Management.

18. Sandia National Laboratories. 2021. "“BIG' Energy Storage: Priorities and Pathways to Long-Duration Energy Storage.” DOE Long-Duration Energy Storage Workshop, 9-10 March 2021.

19. Long Duration Energy Storage Association of California. 2021. "Long Duration Energy Storage in California.” https://www.storeenergyca.org/background

20. J. Spector. 2020. "The First Major Long-Duration Storage Procurement Has Arrived." Greentech Media. https://www.greentechmedia.com/articles/read/the-first-long-durationstorage-procurement-has-arrived

21. M. Tuttman and S. Litzelman. 2020. "Why Long-Duration Energy Storage Matters." ARPA-E Blog Post. https://arpa-e.energy.gov/news-and-media/blog-posts/why-longduration-energy-storage-matters

22. U.S. Department of Energy Office of Energy Efficiency and Renewable Energy. 2021. "Long Duration Storage Shot." https://www.energy.gov/eere/long-duration-storage-shot

23. C. Amy, M. Pishahang, C. C. Kelsall, A. LaPotin, and A. Henry. 2021. "High-temperature Pumping of Silicon for Thermal Energy Grid Storage.” Energy 233: 121105. https://doi.org/10.1016/j.energy.2021.121105

24. Z. Ma, X. Wang, P. Davenport, and J. Martinek. 2021. "Economic Analysis of an Electric Thermal Energy Storage System Using Solid Particles for Grid Electricity Storage." 
Proceedings of the ASME 2021 15th International Conference on Energy Sustainability, 16-18 June 2021. https://doi.org/10.1115/ES2021-61729

25. P. Albertus, J. Manser, and S. Litzelman. 2020. "Long-duration electricity storage applications, economics, and technologies." Joule 4: 21-32. https://doi.org/10.1016/j.joule.2019.11.009

26. J. A. Dowling, K. Z. Rinaldi, T. H. Ruggles, S. J. Davis, M. Yuan, F. Tong, N. S. Lewis, and K. Caldeira. 2020. "Role of Long-Duration Energy Storage in Variable Renewable Electricity Systems." Joule 4: 1907-1928. https://doi.org/10.1016/j.joule.2020.07.007

27. M. Jafari, M. Korpås, and A. Botterud. 2020. "Power system decarbonization: Impacts of energy storage duration and interannual renewables variability." Renewable Energy 156: 1171-1185. https://doi.org/10.1016/j.renene.2020.04.144

28. R. H. Schulte and F. C. Fletcher. 2020. "On the Value of Time-Diversified Renewable Energy Using Interregional HVDC Transmission.” Electricity Journal 33 (10): 106861. https://doi.org/10.1016/j.tej.2020.106861

29. J. Zhang, O. J. Guerra, J. Eichman, and M. A. Pellow. 2020. "Benefit Analysis of LongDuration Energy Storage in Power Systems with High Renewable Energy Shares." Frontiers in Energy Research 8: 313. https://doi.org/10.3389/fenrg.2020.527910

30. F. J. de Sisternes, J. D. Jenkins, and A. Botterud. 2016. "The value of energy storage in decarbonizing the electricity sector." Applied Energy 175: 368-379. https://doi.org/10.1016/j.apenergy.2016.05.014

31. H. B. Ratz, R. Robichaud, L. Bird, and N. Hutchinson. 2020. The Role of Long-Duration Energy Storage in Deep Decarbonization: Policy Considerations. Washington, D.C.: World Resources Institute. http://www.indiaenvironmentportal.org.in/files/file/role-longduration-energy-storage-deep-decarbonization-policy.pdf

32. Z. Ma, J. D. McTigue, P. Li, R. Yang, Y. Ding, and C. N. Markides (Eds.). 2020. "LongDuration and Long-Term Energy Storage for Renewable Integration." Frontiers Research Topic. https://www.frontiersin.org/research-topics/10251/long-duration-and-long-termenergy-storage-for-renewable-integration

33. J. D. Ogland-Hand, J. Bielicki, B. Adams, T. A. Buschek, and M. O. Saar. 2021. "Using Sedimentary Basin Geothermal Resources to Provide Long-Duration Energy Storage." Presented at the World Geothermal Congress, 24-27 October 2021, Reykjavik, Iceland. https://doi.org/10.3929/ethz-b-000467595

34. A. N. C. Edington. 2019. "The Role of Long Duration Energy Storage in Decarbonizing Power Systems.” Master's thesis, Massachusetts Institute of Technology.

35. J. Gifford, Z. Ma, and P. Davenport. 2020. "Thermal Analysis of Insulation Design for a Thermal Energy Storage Silo Containment for Long-Duration Electricity Storage." Frontiers in Energy Research 8. https://doi.org/10.3389/fenrg.2020.00099 
36. C. K. Ho and A. Ambrosini. 2020. "Chapter 12: Thermal Energy Storage Technologies." In 2020 U.S. DOE Energy Storage Handbook. Albuquerque, NM: Sandia National Laboratories.

37. J. Bistline, G. Blanford, T. Mai, and J. Merrick. 2021. "Modeling variable renewable energy and storage in the power sector." Energy Policy 156. https://doi.org/10.1016/j.enpol.2021.112424

38. J. E. T. Bistline and G. J. Blanford. 2021. "Impact of carbon dioxide removal technologies on deep decarbonization of the electric power sector." Nature Communications 12. https://doi.org/10.1038/s41467-021-23554-6

39. E. Du, H. Jiang, J. Xiao, J. Hou, N. Zhang, and C. Kang. 2021. "Preliminary analysis of long-term storage requirement in enabling high renewable energy penetration: A case of East Asia." IET Renewable Power Generation 15 (6): 1255-1269.

https://doi.org/10.1049/rpg2.12104

40. N. A. Sepulveda, J. D. Jenkins, A. Edington, D. S. Mallapragada, and R. K. Lester. 2021. "The design space for long-duration energy storage in decarbonized power systems." Nature Energy 6: 506-516. https://doi.org/10.1038/s41560-021-00796-8

41. J. Spector. 2020. "So, What Exactly Is Long-Duration Energy Storage?" Greentech Media. https://www.greentechmedia.com/articles/read/so-what-exactly-is-long-duration-storageexplained

42. Renewable Energy World. 2017. "A Longer Look at Long-duration Energy Storage." https://www.renewableenergyworld.com/storage/a-longer-look-at-long-duration-energystorage/\#gref

43. U.S. Environmental Protection Agency. 2021. "Summary of the Clean Air Act." https://www.epa.gov/laws-regulations/summary-clean-air-act

44. A. W. Frazier, W. Cole, P. Denholm, D. Greer, and P. Gagnon. 2020. "Assessing the potential of battery storage as a peaking capacity resource in the United States." Applied Energy 275: 115385. https://doi.org/10.1016/j.apenergy.2020.115385

45. K. Carden and N. Wintermantel. 2019. Energy Storage Capacity Value on the CAISO System. Hoover, AL: Astrapé Consulting.

46. K. Carden, N. Wintermantel, and A. Krasny. 2019. Capacity Value of Energy Storage in PJM. Hoover, AL: Astrapé Consulting.

47. R. Sioshansi, S. H. Madaeni, and P. Denholm. 2014. "A Dynamic Programming Approach to Estimate the Capacity Value of Energy Storage." IEEE Transactions on Power Systems 29: 395-403. https://doi.org/10.1109/TPWRS.2013.2279839

48. P. Denholm, W. Cole, A. W. Frazier, K. Podkaminer, and N. Blair. 2021. The Four Phases of Storage Deployment: A Framework for the Expanding Role of Storage in the U.S. Power 
System. Golden, CO: National Renewable Energy Laboratory.

https://www.nrel.gov/docs/fy21osti/77480.pdf

49. J. Cochran and P. Denholm (Eds.). 2021. The Los Angeles 100\% Renewable Energy Study (LA100). Golden, CO: National Renewable Energy Laboratory. NREL/TP-6A20-79444. https://maps.nrel.gov/la100/

50. U.S. Department of Energy Office of Energy Efficiency and Renewable Energy. 2021. Solar Futures Study. Washington, D.C.: EERE. https://www.energy.gov/sites/default/files/2021-09/Solar\%20Futures\%20Study.pdf 


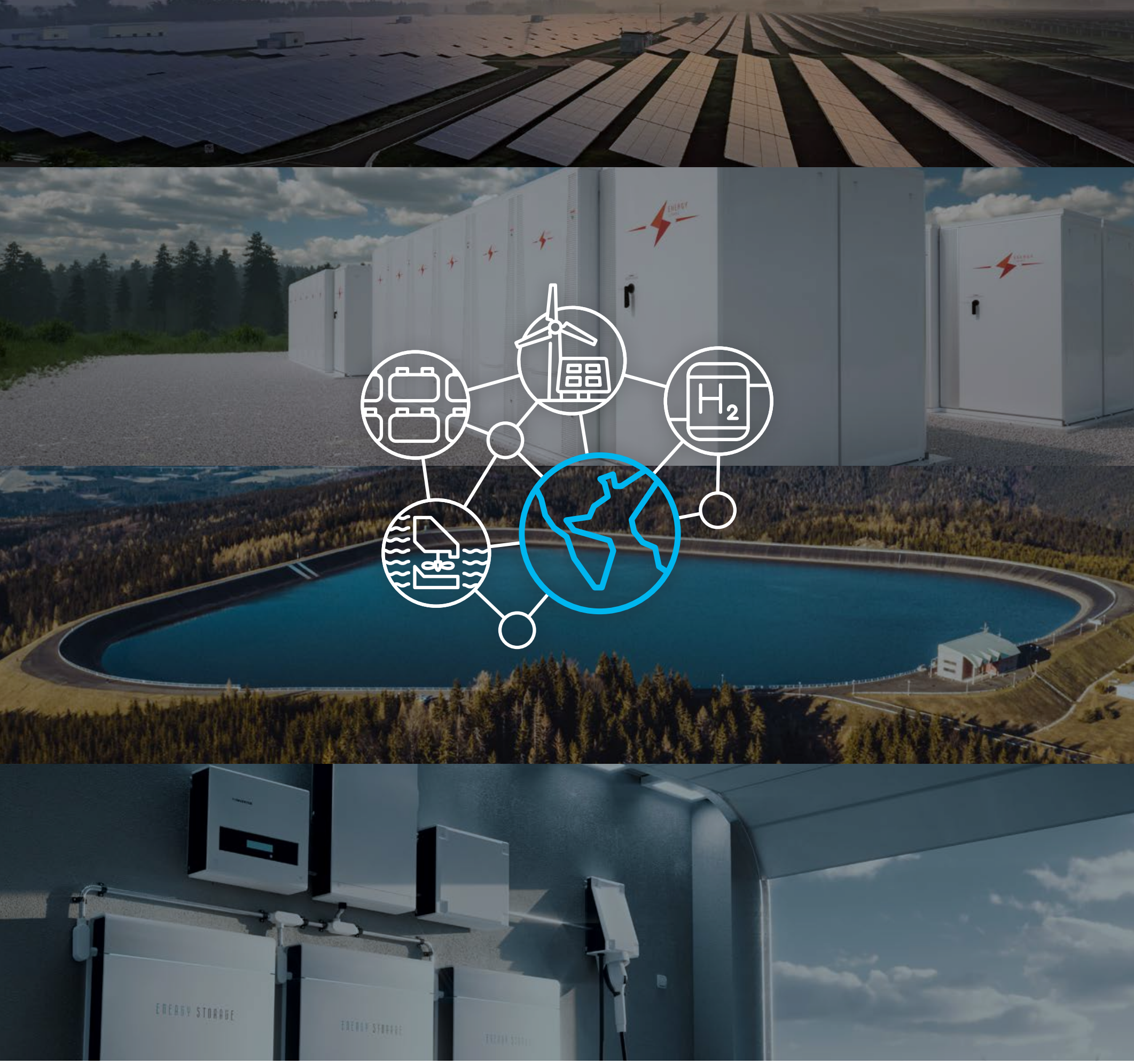

National Renewable Energy Laboratory

15013 Denver West Parkway, Golden, CO 80401 303-275-3000 • www.nrel.gov

NREL prints on paper that contains recycled content.
NREL is a national laboratory of the U.S. Department of Energy Office of Energy Efficiency and Renewable Energy Operated by the Alliance for Sustainable Energy, LLC NREL/TP-6A40-80583 • November 2021 